\title{
How I feed patients intravenously
}

\section{By A. J. W. Sıм, Academic Surgical Unit, St Mary's Hospital, London W2}

The major problems associated with intravenous nutrition relate to the techniques employed, so much so that patients have probably been deprived of nutritional support because of fear of complications which might arise as a direct result of this treatment. It is not the remit of the present paper to argue the case for when and why intravenous nutrition should be employed; however, the author's contention is that in patients with non-accessible or non-functioning gastrointestinal tracts, good reasons are needed before an active decision to starve a patient for longer than 5 or $6 \mathrm{~d}$ is made. This contention is based on the assumption that a safe and simple method to provide intravenous nutrients is available. The present paper describes a system which meets these conditions.

The aspects of intravenous feeding that need consideration are catheter insertion, catheter sepsis, flow control, nutrient type and delivery systems.

\section{Catheter insertion}

In order to ensure reliable delivery of hypertonic nutrient solutions, perhaps for prolonged periods of time, a catheter has to be inserted so that its tip lies in a large calibre vein with a rapid blood flow (preferably the superior vena cava) to allow dilution of the solution and minimize venous endothelial damage. Intravenous feeding using peripheral forearm veins has its proponents (Daly et al. 1985) but the inconvenience to the patient of having regular resiting of intravenous cannulas (to avoid thrombophlebitis), the restriction of arm movement and the possibility that less than optimum quantities of nutrients will be supplied must be balanced against the hazards of central vein catheterization.

Access to major veins can either be by a blind percutaneous technique or by direct exposure of the vein which is to be cannulated. The former relies on a sound knowledge of the surface anatomy of the vessel to be cannulated and a tacit belief that anatomical variations are sufficiently infrequent not to warrant concern; in addition it is necessary to appreciate that in disease states, particularly hypovolaemia, the size of the vein might alter considerably and provide difficulties in cannulation. Direct exposure requires a degree of surgical expertise and is perhaps more time-consuming than the blind percutaneous technique. Both techniques should be carried out in an operating theatre and the catheter screened into position with $x$-ray image intensification if available. Hypertonic solutions should not be infused through the catheter until the correct positioning of the catheter tip has been confirmed by $x$-ray. In the hands of clinicians regularly inserting catheters by one of the blind techniques, particularly via the subclavian vein, low complication rates occur. In the less-experienced hands of those who are 
either learning to insert catheters or who do so infrequently, complications such as pneumothorax and major vessel damage can be expected (Bernard \& Stahl, I97I). Avoidance of complications in one of the direct-exposure techniques is demonstrated by the experience of the Surgical Nutritional Advisory Group at the Glasgow Royal Infirmary with cutdowns to the cephalic vein. The first sixty-five catheter insertions were carried out by nine individuals, inserting between one and thirty catheters each; no major complications occurred.

The principal veins used in the direct-exposure technique are the internal jugular (Benotti et al. 1977), subclavian (Oosterlee \& Dudley, 1980), external jugular and cephalic veins (Ellis \& Fielding, 1977).

The direct-exposure technique requires an incision which will inevitably leave a scar and attention should be paid to the cosmetic appearance of this scar, as the majority of patients who are intravenously fed survive. The cephalic vein cutdown, although safe, is undesirable because the scar can be both unsightly and conspicuous. The internal jugular approach leaves a small, narrow scar which in a recent study by Stotter et al. (1984) was shown to be better than the subclavian approach. In addition the internal jugular approach took less time than the subclavian. Most cutdowns were carried out under local anaesthetic and more difficulties were encountered with the internal jugular if the patient was restless. Since October 1982 we have inserted catheters principally by the internal jugular route. For various reasons, e.g. previous cutdown or tracheostomy, it was not always possible to use the internal jugular vein. Table I shows our experience up to March 1985 , the internal jugular vein being used in $56 \%$ of insertions. Wherever possible a right-sided $(75 \%)$ vein was used because of the more direct course of the vein to the superior vena cava.

\section{Catheter sepsis}

Once inserted, the major problem with the catheter is that of sepsis. Like many foreign bodies introduced into the body, venous catheters, once infected with organisms, act as a septic focus which is usually unresponsive to normal defence mechanisms and antibiotics. It is therefore imperative that catheters are cared for with full aseptic precautions, a responsibility which falls on the nursing staff whose duty it is to manage the day-to-day aspects of intravenous feeding. Since the late

Table. 1. Route of insertion of catheters in intravenously-fed patients (October 1982-March 1985)

\begin{tabular}{lccc} 
& \multicolumn{3}{c}{ No. of insertions } \\
\cline { 2 - 4 } Vein & Right & Left & Total \\
Internal jugular & 79 & 23 & 102 \\
Subclavian & 24 & 10 & 34 \\
External jugular & 18 & 4 & 22 \\
Cephalic & 14 & 7 & 21 \\
Saphenous & 1 & 1 & 2 \\
Total & 136 & 45 & 181
\end{tabular}


1970s, reports of catheter sepsis due to the skin commensal Staphylococcus epidermidis have appeared. This organism is particularly well adapted to infect catheters as it produces a 'sticky' slime substance (Christensen et al. 1982) and has the ability to etch into the catheter surface. In the report of Deitel et al. (1983) the occurrence of infection with this organism was described as an 'outbreak'. A similar outbreak occurred in our unit: ninety-one catheters were inserted at this time and information to allow definition of catheter sepsis was available in seventy. Peripheral and drawback blood cultures and cultures of the catheter tip were carried out on removal of the catheter. Catheter sepsis was defined as culture of the same organism from at least two of these three cultures in a patient whose pyrexia decreased to normal on removal of the catheter. Twenty-seven $(39 \%)$ were infected with one episode of sepsis every forty-nine catheter days, twenty-three being infected with $S$. epidermidis. Faced with this unacceptable catheter sepsis rate which threatened our intravenous feeding programme the catheter care policy was changed to what is now referred to as one of junctional care (Waterfield et al. I985). Three principal changes occurred. First the catheter was changed to a type which did not require an extension. This reduced the number of junctions in the system from two to one. Second, 'cleaning' of the junction at the time of changing the nutrient supply was carried out using an alcoholic solution instead of an aqueous one: this kills bacteria more rapidly. Third, the junction, instead of lying on the skin and being covered with a dry gauze dressing, was protected by a rigid plastic shield containing a gauze sponge impregnated with Povidone iodine (Travenol). After this junctional care policy was introduced, the catheter sepsis rate was reduced to $8 \%$ with one episode of sepsis every $375 \mathrm{~d}$ in the next seventy-two catheters for which full information was available.

\section{Flow control}

Administration of intravenous nutrient solutions needs to be well controlled in terms of total volume infused and consistency of flow rate. Flow control can vary from the unsophisticated and unreliable gravity flow, with roller clamp control, to the more advanced, positive-pressure, constant-volume pumps employing the latest electronic advances. In between these come flow-control devices which are more reliable than the roller clamp and do not have the drawbacks of the pumps. Such a control device is the silicone-membrane proportionating valve (Isoflux; Van Leer), which has a chamber divided by a flexible silicone membrane into inflow and outflow sections connected to each other by a feeder tube with a controllable flow rate. When the pressure in the inflow side increases because of flow from a reservoir, the membrane is distorted to occlude the outflow channel, equilibration of pressures at a controlled rate by the feeder tube allows the silicone membrane to return to the neutral position thus opening the outflow channel and allowing flow out. In reality these changes occur rapidly, allowing smooth, well-controlled flow of solutions. Clinical studies carried out in the Academic Surgical Unit at St Mary's Hospital, London (Kapadia et al. $198 \mathrm{r}$ ) have shown that the nursing workload was lower with the Isoflux than with a roller clamp: the number of flow control changes 
necessary in delivering intravenous nutrients from thirty-one bags was reduced from 3.24 to $1.26 / 24 \mathrm{~h}$. There do not appear to be any comparative studies with constant-volume pumps; however, the initial high cost, the necessity of having back-up pumps in case of mechanical failure and the requirement that all nursing staff are acquainted with pump usage are drawbacks which need to be considered. The proportioning valve can be connected to the nutrient reservoir in the pharmacy and delivered to the ward complete so that the only nursing manoeuvres required are the connection of the assembly to the central venous catheter and the setting of the flow rate.

\section{Nutrient type and delivery system}

A variety of nutrient solutions are available for intravenous infusion and the principal choice is which of the amino acid solutions to use. Evidence of the superiority of one amino acid solution over another is sparse and out of date and the decision will usually be made on personal preference. It is important though to ensure that when solutions are mixed they are compatible, this is more likely if all the products come from the same company. There is much debate about use of fat emulsion as an energy source. In most intravenous feeding, the provision of $4 \mathrm{I} 84$ $\mathrm{kJ}(\mathrm{r} 000 \mathrm{kcal}) / \mathrm{d}$ as fat is safe and efficacious and may reduce the metabolic complications associated with giving an additional $25^{\circ} \mathrm{g}$ glucose. Fat emulsions are more expensive than glucose solutions but the savings made by use of glucose alone will be small when taken in context of the total cost of managing a seriously-ill patient (a I d course of intravenous gentamicin and metronidazole is over $40 \%$ more expensive than provision of $4 \mathrm{I} 84 \mathrm{~kJ}$ ( $1000 \mathrm{kcal}$ ) as intravenous fat emulsion).

Intravenous nutrients can be administered from separate bottles connected by individual, ' $\mathrm{Y}$ ' or even ' $\mathrm{W}$ ' junctions but these systems are difficult to control and take up considerable nursing time. The introduction of the 3 -litre bag allowed solutions of amino acids, glucose, electrolytes, vitamins and trace minerals to be mixed under sterile laminar air conditions into one container thus reducing nursing workload and improving flow control. Fielding et al. (198I) have reported their experience with 1594 3-litre bags. The Surgical Nutritional Advisory Group at Glasgow Royal Infirmary started with the 3 -litre bag in October 1979, using a policy of one standard nutritional intake for all patients. In the period to April 1981,6853 -litre bags were used; $95 \%$ of these were nutritionally standard and changes to a standard electrolyte intake were necessary in $48 \%$, potassium being the commonest electrolyte to be altered.

The introduction of 3 -litre bags considerably simplified nutrient provision but when fat emulsion was to be given it was necessary to infuse this separately. Mixing fat emulsion with the other components in a 3 -litre bag to give a complete nutritive mixture had been reported as long ago as 1973 (Solassol et al. 1973) and by 1980 this group had reported their experience of 64095 mixtures administered to 2669 patients (Solassol \& Joyeux, 1980). Others have reported on 9roo d of intravenous feeding with complete nutritive mixtures in 395 patients (Sitges-Serra 
Table. 2. Details of 3-litre nutrient mixture bags

\begin{tabular}{|c|c|c|c|c|c|c|c|}
\hline \multirow[b]{3}{*}{$\begin{array}{c}\text { Regimen } \\
\text { no. }\end{array}$} & \multirow[b]{3}{*}{$\begin{array}{c}\text { Nitrogen } \\
(\mathrm{g} / \mathrm{d})\end{array}$} & \multicolumn{4}{|c|}{ Non-protein energy } & \multirow[b]{3}{*}{$\begin{array}{c}\text { No. of } \\
\text { bags }\end{array}$} & \multirow[b]{3}{*}{$\begin{array}{l}\text { No. of } \\
\text { patients }\end{array}$} \\
\hline & & \multicolumn{2}{|c|}{ Carbohydrate } & \multicolumn{2}{|c|}{$\underbrace{\text { Fat }}$} & & \\
\hline & & kJ & kcal & kJ & kcal & & \\
\hline 1 & $9 \cdot 4$ & 3347 & 800 & 4184 & 1000 & 24 & 5 \\
\hline 2 & $9 \cdot 4$ & 5020 & 1200 & 4184 & 1000 & 75 & 6 \\
\hline 3 & $14 \cdot 1$ & $4^{18} 8_{4}$ & 1000 & 4184 & 1000 & 887 & 89 \\
\hline 4 & $14 \cdot 1$ & 5857 & 1400 & 4184 & 1000 & 47 & 9 \\
\hline
\end{tabular}

et al. 1983). Concern about the stability of the fat emulsion in complete nutritional mixtures delayed their introduction into the UK. Stability studies eventually confirmed that fat particle size was not sufficiently disturbed to risk fat embolism (Jeppsson \& Sjoberg, 1984). Sim et al. (1984) fed ninety-six patients with a mean of 10.8 bags of complete nutritive mixture each (range $I-16_{3}$ ). Table 2 shows the four regimens, their nitrogen and energy contents, the number of bags of each regimen prepared and the number of patients to whom each regimen was administered.

The introduction of the single 3 -litre bag system of complete nutrient delivery has considerably simplified nursing procedures. We have not seen any visible signs of destabilization (cracking) of the emulsion. 'Creaming' does occur but this has not produced any clinical problems. Fatty serum, indicating poor fat utilization, has not been observed.

\section{Conclusions}

After the decision has been made to feed a patient intravenously, the catheter has been inserted and the nutrient intake defined, intravenous feeding is carried out by the nursing staff. Often the patients being fed have complex nursing problems and thus if intravenous feeding is to be effectively performed it needs to be standardized, simple and safe. The system described here of: ( $I$ ) direct venous exposure for insertion of tunnelled sialastic catheters; (2) care of catheter/giving set junction; (3) proportionating valve control of nutrient delivery; and (4) complete nutrient mixtures in 3 -litre bags prepared in sterile laminar flow facilities; goes a long way to meeting these criteria. Changes in technique can improve results and those people involved in intravenous feeding should keep an open mind about new and different aspects of intravenous feeding and incorporate them as and when they are appropriate.

\section{REFERENCES}

Benotti, P. N., Bothe, A., Miller, J. D. B. \& Blackburn, G. L. (1977). Surgery, Gynecology and Obstetrics 144, 574- 576 .

Bernard, R. W. \& Stahl, W. M. (1971). Annals of Surgery 173, 184-190. 
Christensen, R. D., Simpson, W. A., Bisno, A. L. \& Beachy, E. R. (I982). Fournal of Infection and Immunology 37, 318-326.

Daly, J. M., Masser, E., Hansen, L. \& Canham, J. E. (1985). Fournal of Parenteral and Enteral Nutrition 9, 196-299.

Deitel, M., Krajden, S. \& Saldanha, C. F. (1983). Fournal of Parenteral and Enteral Nutrition 7, $569-572$.

Ellis, B. W. \& Fielding, L. P. (1977). In Rob and Smith's Operative Surgery. General Principles, 3rd ed., pp. 26-34 [H. Dudley and W. Pories, editors]. Sevenoaks: Butterworths.

Fielding, L. P., Humfrees, A. M., Mouchizadeh, J., Dudley, H. A. F. \& Gilmour, M. (1981). Pharmaceutical fournal 590-592.

Jeppsson, R. K. \& Sjoberg, B. (1984). Clinical Nutrition 2, $18-19$.

Kapadia, C. R., Biglin, J. E. J., Hall, P. \& Fielding, L. P. (1981). British Gournal of Intravenous Therapy 2, $18-19$.

Oosterlee, J. \& Dudley, H. A. F. (1980). Lancet i, 19-20.

Sim, A. J. W., Ward, H. C., Humfrees, A. \& Dudley, H. A. F. (1984). Proceedings of the Nutrition Society 43, $122 \mathrm{~A}$.

Sitges-Serra, A., Jaurrieta, E., Pallares, R., Lorente, L. \& Sitges Creus, A. (1983). In Advances in Clinical Nutrition, pp. 207-212 [I. D. A. Johnson, editor]. Lancaster: MTP Press.

Solassol, C. \& Joyeux, H. (1980). Acta Chirurqica Scandinavia 498 (Suppl.), $5^{1-1} 53$.

Solassol, C., Joyeux, H. \& Serrou, B. (1973). fournal de Chirurqie 105, 15 -24.

Stotter, A., Sim, A. J. W. \& Dudley, H. A. F. (1984). British Yournal of Parenteral Therapy 5, I $93^{-201 .}$

Waterfield, A. H., Stotter, A. T., Sim, A. J. W. \& Dudley, H. A. F. (1985). Clinical Nutrition 4 (Suppl.), 67. 